Pub. 594

\title{
Transporte-maturação de oócitos bovinos em palhetas
}

\author{
Transport-maturation of bovine oocytes in straws \\ Janaína Vanuci Tessmann ${ }^{1}$, Fabrício Desconzi Mozzaquatro ${ }^{1}$, Lucio Pereira Rauber ${ }^{1}$, \\ Márcia Vendrusculo dos Santos ${ }^{2}$, Ricardo Monteiro Chequim², Mari Lourdes Bernardi ${ }^{3}$, \\ Carlos Antonio Mondino Silva ${ }^{4} \&$ Mara lolanda Batistella Rubin ${ }^{4}$
}

\begin{abstract}
RESUMO
A demanda pela aspiração folicular associada à produção in vitro de embriões, no Brasil, aumentou com o objetivo de acelerar o ganho genético do rebanho bovino. A técnica, no entanto, apresenta limitações, especialmente relacionadas ao tempo e às condições de transporte dos oócitos até o laboratório. Para avaliar o uso de palhetas de $0,25 \mathrm{~mL}$ no transportematuração simulado, complexos cumulus-oócitos (CCO) de vacas de frigorífico foram maturados in vitro. No experimento I, efetuou-se a maturação em meio TCM-199, em placas de 4 poços, em estufa a $38,5^{\circ} \mathrm{C}, 5 \% \mathrm{CO}_{2}$, por $24 \mathrm{~h}$ (grupo controle) e em palhetas, em meio TCM-Hepes, mantidas por $6 \mathrm{~h}$ em banho-maria (grupo BM) ou garrafa térmica (grupo T), a $38,5^{\circ} \mathrm{C}$. Nestes dois grupos, a maturação foi completada em placas, por $18 \mathrm{~h}$, nas mesmas condições do grupo controle. No experimento II, simulouse o transporte em palhetas, em meio TCM-Hepes, a $38,5^{\circ} \mathrm{C}$, por $24 \mathrm{~h}$, em estufa (grupo palheta). O grupo controle foi semelhante ao do experimento I. A fecundação (=D0) foi efetuada em meio TALP-Fert, por 18h, e o cultivo foi efetuado em meio SOFaaci, por 8 dias, em ambos os experimentos. As taxas de blastocistos em D7, no experimento I, foram semelhantes $(\mathrm{P}>0,05)$ para os grupos controle (31\%;97/312), BM (21\%;64/301) e T (31\%;94/298). No experimento II, não houve diferença $(\mathrm{P}>0,05)$ nas taxas de blastocistos em D7 entre os grupos controle $(30 \% ; 44 / 145)$ e palheta $(20 \% ; 29 / 139)$. O número de células dos blastocistos eclodidos não diferiu entre os grupos, em ambos os experimentos $(\mathrm{P}>0,05)$. As palhetas ofereceram condições seguras e práticas para o transporte-maturação de CCO em TCM-Hepes, em garrafa térmica a $38,5^{\circ} \mathrm{C}$, por 6 h. Portanto, sua aplicação é possível nos programas de aspiração folicular e produção in vitro de embriões bovinos.
\end{abstract}

Descritores: bovinos, palhetas, Hepes, transporte, PIV.

\section{ABSTRACT}

The interest for bovine ovum pick-up associated with the embryo in vitro production process in Brazil is growing, seeking a fast genetic improvement of the herd. However, the whole procedure shows limitations especially regarding time and conditions for the transport of oocytes. To evaluate the use of $0.25 \mathrm{~mL}$ straws during the transportmaturation process, cumulus-oocyte complexes (COC) obtained from slaughtered cows were selected for in vitro maturation. In experiment I, the maturation was performed in 4-well dishes, with TCM-199 medium, in an incubator with 5\% $\mathrm{CO}_{2}$, at $38.5^{\circ} \mathrm{C}$, for $24 \mathrm{~h}$ (control group) and into $0.25 \mathrm{~mL}$ straws containing TCM-Hepes medium, maintained in water bath (BM group) or in a thermo bottle (T group) at $38.5^{\circ} \mathrm{C}$, for $6 \mathrm{~h}$. In these two groups, maturation was completed in 4-well dishes, for $18 \mathrm{~h}$, in the same conditions of the control group. In experiment II, the transport-maturation was simulated in straws with TCM-Hepes medium, at $38.5^{\circ} \mathrm{C}$, in an incubator, for $24 \mathrm{~h}$ (straw group). The control group was similar to that described for experiment I. The fertilization (Day 0) was accomplished in TALP-FERT for $18 \mathrm{~h}$ and the culture in SOFaaci medium, for 8 days, in both experiments. In experiment I, blastocyst rates at D7 were similar ( $\mathrm{P}>0.05)$ for control $(31 \%$; 97/312), BM (21\%; 64/301) and T (31\%;94/298) groups. In Experiment II, no differences ( $\mathrm{P}>0.05)$ were observed between control (30\%; 44/145) and straw $(20 \% ; 29 / 139)$ groups. Embryo cell number of hatched blastocysts was similar between groups, in both experiments $(\mathrm{P}>0.05)$. The straws offered a safe and practical method for bovine oocyte transport in TCM-Hepes, in thermo bottles, at $38.5^{\circ} \mathrm{C}$, for $6 \mathrm{~h}$. Therefore, its application is possible in programs of oocyte aspiration and in vitro embryo bovine production.

Key words: bovine, straws, Hepes, transport, PIV. CNPq/UFSM, Santa Maria, RS. ${ }^{3}$ Departamento de Zootecnica da Faculdade de Agronomia, UFRGS, Porto Alegre, RS. ${ }^{4}$ Embryolab - Departamento de Clínica de Grandes Animais, Centro de Ciências Rurais, UFSM CORRESPONDÊNCIA: M.I.B. Rubin [www.ufsm.br/embryolab ; janavt@hotmail.com]. 


\section{INTRODUÇÃO}

A aspiração folicular transvaginal guiada por ultra-som (OPU), associada à produção in vitro de embriões bovinos (PIV), permite que oócitos imaturos de vacas de alto mérito genético gerem embriões viáveis à transferência. A OPU/PIV, difundida mundialmente, ocupa no mercado agropecuário brasileiro uma posição de destaque. A empresa que mais emprega esta tecnologia comercialmente está sediada no Brasil [2].

O material genético da fêmea, os Complexos Cumulus-Oócitos (CCO), são sensíveis às variações de temperatura e $\mathrm{pH}$. A longa distância entre as fazendas e os laboratórios de produção é um entrave para o transporte de $\mathrm{CCO}$ recuperados de doadoras vivas por OPU e tem sido objeto de várias pesquisas $[3,8,14,23,29,30]$. A maturação in vitro é efetuada em estufa de cultivo com $5 \%$ de $\mathrm{CO}_{2}$ em ar, em meios com bicarbonato que promovem o controle do $\mathrm{pH}$ [9]. Por outro lado, quando não se tem atmosfera gasosa controlada, deve-se adicionar um tampão orgânico como o Hepes $[29,30]$. Uma alternativa para a manutenção dos CCO é em líquido folicular bovino $[14,23,25]$ ou eqüino [22]. O transporte de CCO já foi testado em tubos de $4 \mathrm{~mL}$ [5], em estufa portátil [5,27], em placas mantidas em bolsas plásticas e gaseificadas [20], em tubos Eppendorff de 1,5mL [28], criotubos de $1 \mathrm{~mL}$ [12] e tubos de poliestireno gaseificados mantidos em banho-maria [13,15,17]. Em bubalinos, o trans- porte de CCO foi testado em tubos Falcon, em incubadora portátil [16]. O fato das palhetas serem de baixo custo e de fácil manipulação levou-nos avaliar o modelo de $0,25 \mathrm{~mL}$ para o transporte-maturação de $\mathrm{CCO}$ em TCM-Hepes, por 6h, em garrafa térmica ou banho-maria a $38,5^{\circ} \mathrm{C}$ e, por $24 \mathrm{~h}$, em estufa, sem controle da atmosfera gasosa.

\section{MATERIAIS E MÉTODOS}

\section{Coleta e seleção dos Complexos Cumulus- Oócitos (CCO)}

Ovários bovinos provenientes de frigorífico foram transportados ao laboratório, à temperatura inicial de $30^{\circ} \mathrm{C}$, em solução fisiológica $\left(0,9 \%\right.$ de $\left.\mathrm{NaCl}^{1}\right)$, com $50 \mathrm{mg} / \mathrm{L}$ de estreptomicina ${ }^{1}$ e $100.000 \mathrm{UI} / \mathrm{L}$ de penicilina G-Potássica ${ }^{1}$. No laboratório, os mesmos foram lavados em álcool $70^{\circ} \mathrm{GL}$ e, em seguida, duas vezes em solução fisiológica. Os folículos (diâmetro 2 a $8 \mathrm{~mm}$ ) foram puncionados com agulha $21 \mathrm{G}$ conectada a uma bomba de vácuo ${ }^{2}$ e os CCO recuperados foram mantidos em líquido folicular para identificação sob lupa estereomicroscópica ${ }^{3}$. Imediatamente após, foi realizada a seleção dos $\mathrm{CCO}$ pelo aspecto morfológico [6]. Antes de iniciar as rotinas deste estudo, efetuou-se o controle da temperatura da água em uma garrafa térmica, recipiente utilizado para o transporte-simulado dos complexos cumulus-oócitos, no decorrer do tempo (Figura 1).

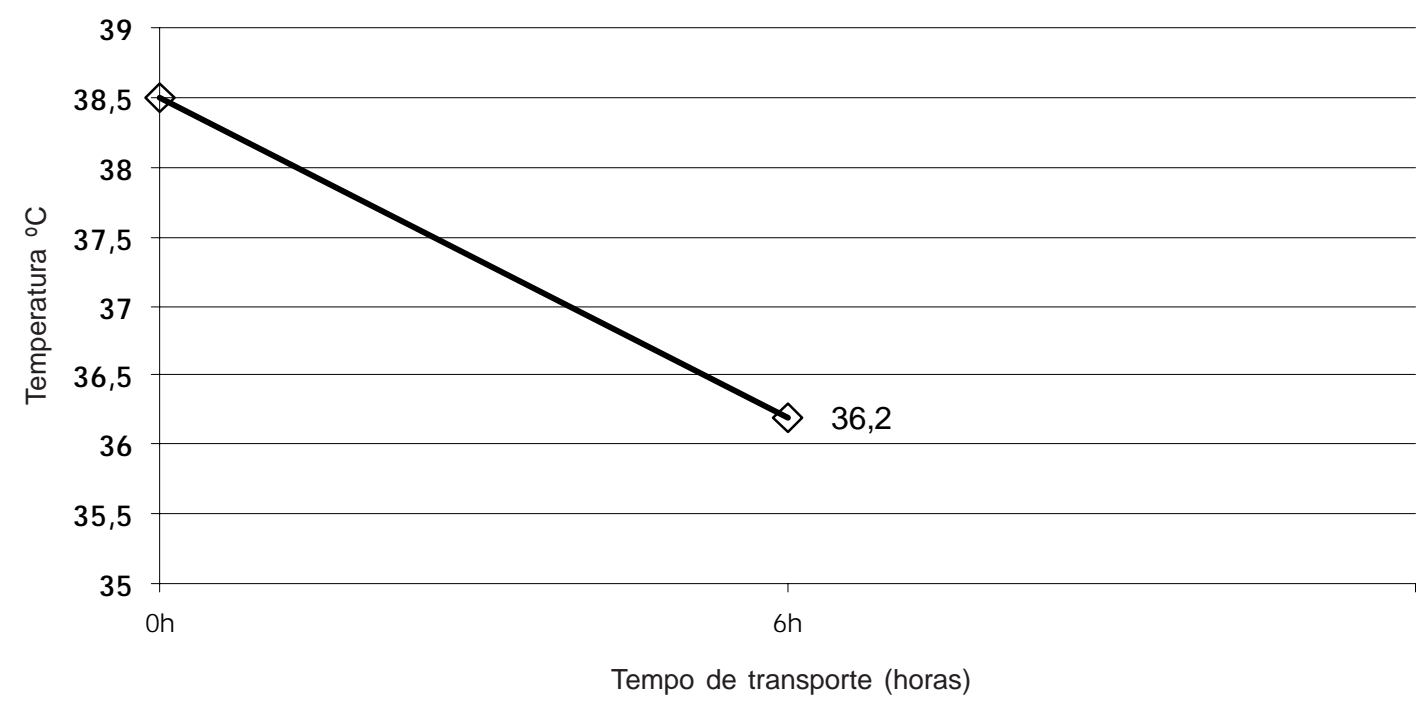

Figura 1. Curva de temperatura da garrafa térmica utilizada no transporte-maturação simulado de Complexos cumulusoócitos (CCO) bovinos em palhetas de $0,25 \mathrm{~mL}$, por 6 horas. 


\section{Maturação in vitro (MIV)}

Em ambos experimentos, os $\mathrm{CCO}$ foram distribuídos aleatoriamente nos tratamentos. Os CCO do grupo controle (C) foram lavados 5 vezes em meio TCM-Hepes com TCM-1994 (Sais de Earle), 6,5mg/ $\mathrm{mL}$ de HEPES (H7006 $\left.{ }^{1}\right), 0,168 \mathrm{mg} / \mathrm{mL}$ de bicarbonato de sódio $\left(\mathrm{S} 5761^{1}\right), 0,022 \mathrm{mg} / \mathrm{mL}$ de piruvato de sódio $\left(\mathrm{P} 4562^{1}\right)$ e $10 \%$ de soro de vaca em estro (SVE). Os CCO (20 a 30) foram maturados in vitro, em $400 \mathrm{~mL}$ de TCM-199 com 3mg/mL de bicarbonato de sódio $\left(\mathrm{S} 5761^{1}\right), 5,957 \mathrm{mg} / \mathrm{mL}$ de Hepes $\left(\mathrm{H} 6147^{1}\right)+0,01 \mathrm{UI}$ de $\mathrm{rFSHh}^{5} / \mathrm{mL}$ e $0,5 \mathrm{mg} / \mathrm{mL}$ de $\mathrm{LH}^{6}$, em placas de quatro poços ${ }^{7}$, por $24 \mathrm{~h}$, em estufa ${ }^{8}$ de cultivo, a $38,5^{\circ} \mathrm{C}$ com $5 \%$ de $\mathrm{CO}_{2}$ em ar e umidade saturada. Os $\mathrm{CCO}$ dos tratamentos foram lavados e envasados com TCM-Hepes + 0,01UI de $\mathrm{rFSHh} / \mathrm{mL}$ e $0,5 \mathrm{mg} / \mathrm{mL}$ de $\mathrm{LH}$, em palhetas ${ }^{9}$ de $0,25 \mathrm{~mL}$, com $5 \mathrm{CCO} /$ palheta $(5$ CCO:50ml de meio).

No experimento I, as palhetas permaneceram por $6 \mathrm{~h}$ em garrafa térmica ${ }^{10}$, com água inicialmente a $38,5^{\circ} \mathrm{C}(\mathrm{T})$, ou em banho-maria a $38,5^{\circ} \mathrm{C}(\mathrm{BM})$, acondicionadas em luvas de procedimento. Após esse período, todos $\mathrm{CCO}$ foram retirados das palhetas, lavados 4 vezes em TCM-Hepes e maturados por $18 \mathrm{~h}$, nas mesmas condições dos CCO do grupo controle.

No experimento II, os CCO-Controle maturaram nas mesmas condições do grupo controle do experimento I. No grupo-Palheta, os CCO foram mantidos em palhetas, com meio TCM-Hepes+LH/FSH, para simular o transporte-maturação sem controle da atmosfera gasosa, permanecendo na estufa de cultivo por $24 \mathrm{~h}$, sob temperatura constante, em bolsas plásticas seladas, impermeáveis a gases.

\section{Fecundação in vitro (FIV)}

Concluída a maturação, em ambos experimentos, os CCO foram transferidos para $400 \mathrm{~mL}$ de meio TALP-FERT [21] com $6 \mathrm{mg} / \mathrm{mL}^{\text {de }}$ BSA $^{1}, 0,22 \mathrm{mg} /$ $\mathrm{mL}$ de piruvato de sódio ${ }^{1}$ e penicilamina+hipotaurina+ epinefrina $\left(\mathrm{PHE}^{1}\right)$. Este meio foi estabilizado por $2 \mathrm{~h}$ e, após, acrescentou-se $30 \mathrm{mg} / \mathrm{mL}$ de heparina ${ }^{1}$. A FIV foi conduzida em estufa de cultivo ${ }^{7}$ a $38,5^{\circ} \mathrm{C}$, com $5 \%$ de $\mathrm{CO}_{2}$ em ar e umidade saturada, por $18 \mathrm{~h}$, com sêmen congelado ( 1 x $10^{6}$ espermatozóides $\left./ \mathrm{mL}\right)$ de um touro Bos taurus, preparado por migração ascendente [21].

\section{Cultivo in vitro}

Em ambos os experimentos, após o período de FIV, os oócitos/zigotos foram submetidos à agitação mecânica por 85 segundos, em TCM-Hepes. O cultivo foi conduzido em $400 \mathrm{~mL}$ de meio SOFaaci - fluído sintético de oviduto [10], com 5\% de soro de vaca em estro, em placas de cultivo celular com 4 poços ${ }^{7}$, sob óleo mineral ${ }^{1}$, acondicionadas em bolsas com $5 \%$ de $\mathrm{CO}_{2}, 5 \%$ de $\mathrm{O}_{2}$ e $90 \%$ de $\mathrm{N}_{2}$, mantidas em estufa a $38,5^{\circ} \mathrm{C}$, por 8 dias.

A maturação, fecundação e cultivo in vitro nos diferentes tratamentos foram conduzidos simultaneamente, mas em experimentos independentes com 13 (Experimento I) e 5 (Experimento II) repetições. Considerando-se a data da fecundação como dia zero (D0), as taxas de clivagem e de blastocistos foram avaliadas em D2 e D7, respectivamente. Em D9, foi avaliado o desenvolvimento até blastocisto expandido e eclodido. Todos os blastocistos eclodidos foram fixados em paraformaldeído a $2 \%$ e corados com Hoechst $(10 \mu \mathrm{L} / \mathrm{mL})$, em PBS salino, para a contagem de células. A visualização foi efetuada em microscópio de epifluorescência com filtro de excitação $(365 \mathrm{~mm})$ e de barreira $(410 \mathrm{~nm})$.

\section{Análise estatística}

O delineamento experimental foi de blocos ao acaso e cada repetição foi considerada um bloco. Os dados referentes às taxas foram submetidos à transformação raiz quadrada e somados à constante de 1,5 para uniformizar a variância das amostras. Aplicouse o método da análise de variância, teste $\mathrm{F}$ e teste de Tukey, em nível de 5\% de significância. Os resultados foram processados pelo programa estatístico SAS, pelo procedimento GLM [24]. Os dados da contagem de células dos blastocistos foram submetidos à transformação logarítmica, antes da análise pelo GLM. As médias foram comparadas pelo teste de Tukey.

\section{RESULTADOS}

Foi verificado que a temperatura da água, dentro da garrafa térmica utilizada para conduzir o transporte-maturação de $\mathrm{CCO}$ em palhetas de $0,25 \mathrm{~mL}$, passou de 38,5 para $36,5^{\circ} \mathrm{C}$ após 6 h (Figura 1 ).

No experimento I, as taxas de clivagem em D2 foram similares $(\mathrm{P}>0,05)$ para $\mathrm{CCO}$ mantidos em palhetas 
em garrafa térmica $(78,8 \%)$, banho-maria $(78,7 \%)$ e grupo controle $(79,5 \%)$. Os índices de blastocistos em D7 e D9, também foram semelhantes ( $\mathrm{P}>0,05$; Figura 2) entre os tratamentos e o grupo controle. O número de células embrionárias de blastocistos eclodidos ou em eclosão (Tabela 1) não foi diferente $(\mathrm{P}>0,05)$ entre os grupos controle, garrafa térmica e banho-maria.

Tabela 1. Número médio de células visualizadas por coloração fluorescente com Hoechst de blastocistos bovinos eclodidos e em eclosão, obtidos com Complexos cumulusoócitos submetidos ao transporte-maturação in vitro em palhetas de $0,25 \mathrm{~mL}$, a $38,5^{\circ} \mathrm{C}$ por 6 horas.

\begin{tabular}{cccc}
\hline & \multicolumn{3}{c}{ Tratamentos } \\
\cline { 2 - 4 } Estágio & Controle (Estufa) & Banho-maria & Garrafa-térmica \\
embrionário & & & \\
\hline Blastocistos & $132,9 \pm 45,5$ & $130,3 \pm 37,9$ & $141,1 \pm 50,0$ \\
eclodidos & $(n=37)$ & $(n=30)$ & $(n=38)$ \\
Blastocistos & $94,3 \pm 27,0$ & $122,5 \pm 35,4$ & $109,3 \pm 36,1$ \\
em eclosão & $(n=7)$ & $(n=6)$ & $(n=6)$ \\
\hline Não houve diferença entre os tratamentos $(P>0,05)$.
\end{tabular}

No experimento II, não houve diferença $(\mathrm{P}>0,05)$ no percentual de clivagem $(86,2$ e $79,1 \%)$, de blastocistos em D7 (30,3 e 20,8\%; Figura 3), nem no número de células dos blastocistos eclodidos (Tabela 2) entre o grupo controle e os CCO mantidos em palhetas, na estufa por $24 \mathrm{~h}$, respectivamente. A produção de blastocistos em $\mathrm{D} 9(14,4 \%)$ do grupo de CCO mantidos em palhetas foi inferior $(\mathrm{P}<0,05)$ à do grupo controle (24,8\%; Figura 3$)$.

Tabela 2. Número médio de células visualizadas por coloração fluorescente com Hoechst de blastocistos bovinos eclodidos, obtidos de Complexos cumulus-oócitos submetidos ao transporte-maturação in vitro em palhetas de $0,25 \mathrm{~mL}, \mathrm{a} 38,5^{\circ} \mathrm{C}$, por 24 horas.

\begin{tabular}{ccc}
\hline Estágio embrionário & Controle & Palheta $0,25 \mathrm{~mL}$ \\
\hline Blastocistos & $105,4 \pm 39,3$ & $\begin{array}{c}118,7 \pm 27,2 \\
(n=4)\end{array}$ \\
eclodidos & $(n=11)$ & $(P>0,05)$.
\end{tabular}

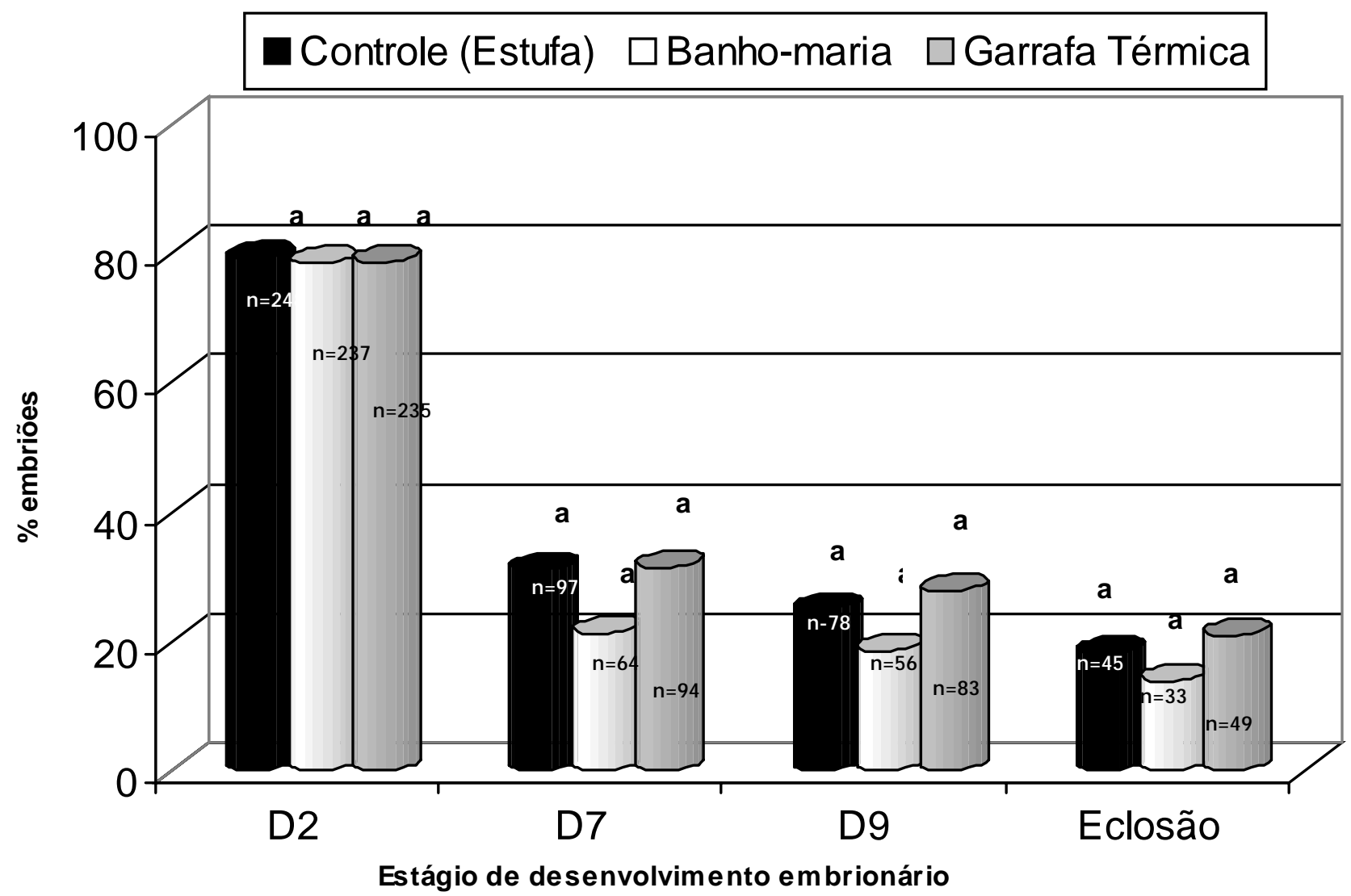

Figura 2. Produção embrionária in vitro com Complexos cumulus-oócitos (CCO) bovinos submetidos ao transporte-maturação simulado em palhetas de $0,25 \mathrm{~mL}$, por 6 horas. 


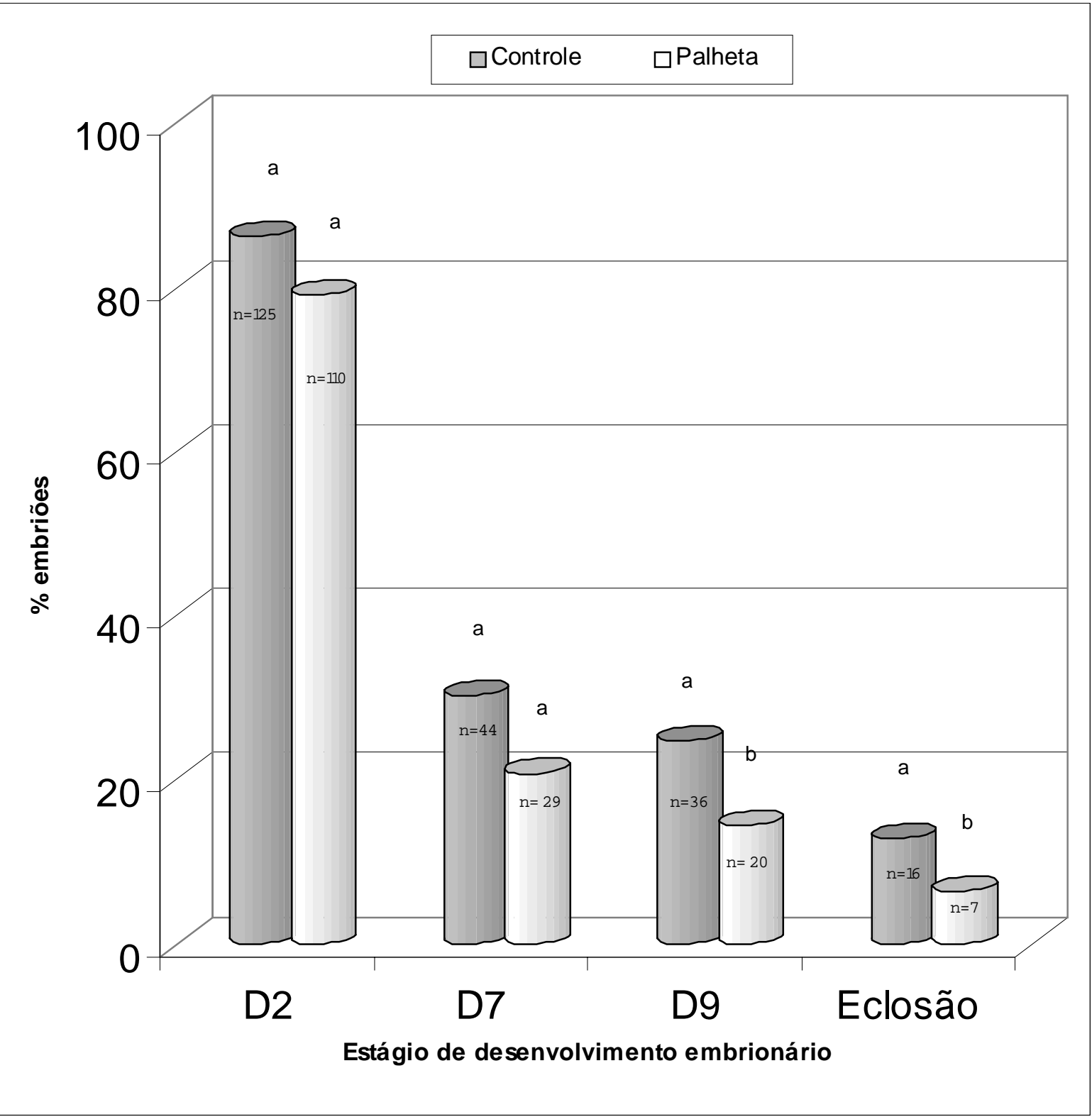

Figura 3. Produção embrionária in vitro com Complexos cumulus-oócitos (CCO) bovinos submetidos ao transporte-maturação simulado em palhetas de $0,25 \mathrm{~mL}$, por 24 horas.

\section{DISCUSSÃO}

A valorização do material genético bovino impulsionou o uso em larga escala da produção in vivo e in vitro de embriões. Um dos fatores limitantes para a OPU/PIV é a perda da qualidade dos oócitos durante o transporte. O meio e o recipiente em que os oócitos são acondicionados são fatores que influenciam na perda da qualidade.

Com o uso de palhetas de $0,25 \mathrm{~mL}$ para transporte dos $\mathrm{CCO}$ em garrafa térmica, houve diminuição da temperatura de 38,5 para $36,5^{\circ} \mathrm{C}$, após $6 \mathrm{~h}$, mas a clivagem e produção de blastocistos manteve-se em percentuais similares aos do grupo controle (Experimento I, Figura 2). Em estudo no qual foi avaliado o efeito da temperatura sobre a produção de embriões in vitro [26], a partir de oócitos bovinos, foi demonstrado que a redução da mesma de $38,5^{\circ} \mathrm{C}$ (10h iniciais) para $37^{\circ} \mathrm{C}$ ( $14 \mathrm{~h}$ finais) não determinou prejuízo na evolução embrionária subseqüente, sugerindo que pequenas variações de temperatura durante a MIV não afetam a produção in vitro.

Quando o transporte de CCO é efetuado sem controle da atmosfera gasosa, procura-se minimizar 
as possíveis alterações de $\mathrm{pH}$ do meio. $\mathrm{O}$ transporte de CCO em tubos de poliestireno de $1,5 \mathrm{~mL}$, em $400 \mathrm{~mL}$ de TCM-Hepes, por $12 \mathrm{~h}$, resultou em produção de blastocistos, em D9, superior $(18,4 \%)$ à observada $(8,6 \%)$ após $18 \mathrm{~h}$ [15]. Para evitar a variação de $\mathrm{pH}$ do meio, $\mathrm{CCO}$ bovinos foram maturados sem controle da atmosfera gasosa, por $24 \mathrm{~h}$, em tubos de poliestireno de $1 \mathrm{~mL}$ repletos de TCM-Hepes, para reduzir o volume de ar [3]. Nesse caso, o pH do meio TCM-Hepes praticamente não variou, durante $24 \mathrm{~h}$, tendo passado de 7,5 para 7,4 e o desenvolvimento embrionário em D7 (38\%) foi semelhante ao observado no grupo controle (36\%), constituído por CCO maturados em TCM-199, em estufa com 5\% $\mathrm{CO}_{2}$. Dessa forma, o meio TCM-Hepes foi utilizado em ambos os experimentos do presente trabalho para evitar a variação de $\mathrm{pH}$, durante o período de transporte simulado.

Nos programas OPU/PIV, em bovinos, é comum a necessidade de efetuar a maturação em pequenos grupos de oócitos. Embora a maturação individual de CCO em meio SOFaa, com álcool polivinílico e $10 \mathrm{ng} / \mathrm{mL}$ de fator de crescimento epidérmico (EGF) tenha permitido a obtenção de $20 \%$ de blastocistos [18], oócitos maturados in vitro individualmente têm, invariavelmente, sua competência oocitária comprometida, bem como o seu subseqüente desenvolvimento embrionário [1,4,7,11]. Deve-se considerar a relação entre o volume de meio e o número de $\mathrm{CCO}$ na avaliação da produção de blastocistos. Quando grupos de 5 a 30 CCO são maturados, na proporção de 1 CCO: $13 \mathrm{~mL}$, há aumento progressivo na produção de blastocistos, com o aumento do número de oócitos [19]. Mantendo a proporção de 1 oócito por $10 \mathrm{~mL}$ de meio, grupos de 10 e 5 oócitos resultam em maiores taxas de blastocistos que os oócitos cultivados individualmente [29]. Em ambos os experimentos do presente estudo, foram utilizados 5 oócitos por palheta, considerado o mínimo necessário para não prejudicar a produção de blastocistos [29].

No experimento II, as taxas de clivagem e de blastocistos em D7 (Figura 3) e número de células dos blastocistos eclodidos, dos grupos controle e palheta, evidenciaram que não houve prejuízo aos CCO transportados. A obtenção de mais de $20 \%$ de blastocistos em D7, importante num programa OPU/PIV, foi obtida aqui, experimentalmente. Em D9, houve menor produção de blastocistos com os CCO maturados nas palhetas por 24h. Mesmo que o meio TCM-Hepes não mostre variação de $\mathrm{pH}$, durante $24 \mathrm{~h}$ de maturação, em tubos de poliestireno de $1 \mathrm{~mL}$ [3], é possível que ele não tenha sido adequado para um período tão longo de maturação, em palhetas. Se o volume reduzido de meio na palheta ou a presença das colunas de ar, vizinhas ao meio, com os oócitos na coluna central da palheta, foram responsáveis por essa diminuição, ainda resta esclarecer. Há ainda que considerar que a avaliação em D9 é usual em pesquisa enquanto que, em programas comerciais de OPU/PIV, os embriões são transferidos em D7. Assim, a ocorrência de diferenças percentuais entre as duas avaliações é discutível, pois a transferência de embriões produzidos in vitro é, sem exceção, efetuada antes do oitavo dia de desenvolvimento.

As palhetas de $0,25 \mathrm{~mL}$ requerem menor volume de meio não gaseificado para acomodar os oócitos e possuem custo inferior a outros recipientes. Elas oferecem, ainda, condições seguras e práticas para o transporte/maturação de CCO em TCM-Hepes, em garrafa térmica a $38,5^{\circ} \mathrm{C}$, por até $6 \mathrm{~h}$, para uso nos programas de aspiração folicular e produção in vitro de embriões bovinos.

\section{CONCLUSÕES}

Palhetas de $0,25 \mathrm{~mL}$ podem ser utilizadas para o transporte-maturação de Complexos CumulusOócitos bovinos em TCM-Hepes, acondicionadas em garrafa térmica a $38,5^{\circ} \mathrm{C}$, sem controle da atmosfera gasosa, por até $6 \mathrm{~h}$, sem prejuízo ao desenvolvimento embrionário in vitro. Adicionalmente, o transportematuração em meio TCM-Hepes a $38,5^{\circ} \mathrm{C}$, por $24 \mathrm{~h}$, é viável para a produção in vitro de embriões bovinos.

Agradecimentos. Ao Prof. Dr. Carlos Augusto Mallmann do LAMIC (UFSM) e ao Prof. José Henrique Souza da Silva (Depto. de Zootecnia, UFSM), pelo apoio à pesquisa. Ao Dr. Neimar Correa da PECPLAN-ABS, Rosário do Sul, RS, pela assistência técnica/auxílio no preparo do sêmen, aos Frigoríficos Silva (Santa Maria) e JG (Caçapava do Sul) que gentilmente cederam os ovários bovinos para este estudo.

\section{Notas Informativas}

${ }^{1}$ Sigma Chemical CO. - P.O. Box 4508, MO., USA. 
${ }^{2}$ Nevoni Equipamento Odonto Médico Hospitalar Ltda.

- Rua Dom João V, 266/280 Lapa 05.075-060 São

Paulo, SP, Brasil.

${ }^{3}$ Carl Zeiss - 73446, Oberkochen, Alemanha.

${ }^{4}$ Gibco BRL, Grand Island, N.Y. 14072, USA.

${ }^{5}$ Serono Pharma S.p.A. - 70123, Bari, Itália (L1930300).

${ }^{6}$ Lutropin - Vetrepharm Inc. London, N6M 1 A3, Ontario, Canada
${ }^{7}$ Nunclon, Nunc Brand Products - Postbox 280, DK4000, Roskilde, Dinamarca.

${ }^{8}$ W.C. Heraeus GmbH. Postfach 1553 D-6450 Hanau 1 , Alemanha.

${ }^{9}$ Minitüb Abfüll - und Labortechnik GmbH \& Co. Hauptstrabe 41 D-84184 Tiefenbach, Alemanha.

${ }^{10}$ Sobral Invicta S/A - Industria Brasileira Al. Manuel Antônio Sobral, 701 - Distr. Industrial. 37.550-000 Pouso Alegre, MG - Brasil.

\section{REFERÊNCIAS}

1 Ahern T.J. \& Gardner D.K. 1998. Culturing bovine embryos in groups stimulates blastocyst development and cell allocation to the inner cell mass. Theriogenology. 49:194.

2 Alvarenga M.A. 2003. A excelência do Brasil em embriões. Informativo bimestral da Tortuga Cia Zootécnica Agrária. Ano 49. 439:3.

3 Alves D.F. 2003. Transporte e maturação in vitro de oócitos bovinos. 47f. Santa Maria, RS. Dissertação (Mestrado em Medicina Veterinária) - Programa de Pós-graduação em Medicina Veterinária, Universidade Federal de Santa Maria.

4 Blondin P. \& Sirard M.A. 1995. Oocyte and follicular morphology as determining characteristics for developmental competence in bovine oocytes. Molecular Reproduction and Development. 41: 54-62.

5 Byrd S.R., Flores-Foxworth G.\& Westhusin M.E. 1995. Normal ovine embryo development following in vitro oocyte maturation in a portable incubator in the absence of $\mathrm{CO}_{2}$. Theriogenology. 43:179.

6 DeLoss F., Vanvliet C., Vanmaurik P. \& Kruip T.A.M. 1989. Morphology of immature bovine oocytes. Gamete Research. 24: 197-204.

7 Fukui Y., Kikuchi Y., Kondo H. \& Mizushima S. 2000. Fertilizability and developmental capacity of individually cultured bovine oocytes. Theriogenology. 53:1553-1565.

8 Galli C., Crotti G., Notari C., Turini P., Duchi R. \& Lazzari G. 2001. Embryo production by ovum pick up from live donors. Theriogenology. 55:1341-1357.

9 Gordon I. 1994. Laboratory Production Of Cattle Embryo. Cambridge: CAB International, University Press, 640p.

10 Holm P., Booth P.J., Schmidt M.H., Greve T. \& Callesen H. 1999. High bovine blastocyst development in a static in vitro production system using SOFaa medium supplemented with sodium citrate and myo-inositol with or without serum-proteins. Theriogenology. 52: 683-700.

11 Jewgenow K., Heerdegen B. \& Muller K. 1999. In vitro development of individually matured bovine oocytes in relation to follicular atresia. Theriogenology. 51: 745-756.

12 Kaiser G., Alberio R., Brum D.S., Bernardi M.L., Silva C.A.M., Rubin M.I.B., Aller J. \& Palma G.A. 1999. Maturação in vitro de oócitos bovinos em criotubos e em estufa portátil. Arquivos da Faculdade de Veterinária UFRGS. 27 (Suppl): 241.

13 Kurtz Filho M. 2003. Maturação e fecundação de oócitos bovinos mantidos em banho-maria. 67f. Santa Maria, RS. Tese (Doutorado em Medicina Veterinária) - Programa de Pós-graduação em Medicina Veterinária, Universidade Federal de Santa Maria.

14 Lehmkuhl R.C. 2001. Desenvolvimento de oócitos bovinos mantidos em líquido folicular. Santa Maria. 16f. Santa Maria, RS. Dissertação (Mestrado em Medicina Veterinária) - Programa de Pós-graduação em Medicina Veterinária, Universidade Federal de Santa Maria.

15 Leivas F.G. 2002. Transporte de oócitos bovinos em meio de maturação sem controle de atmosfera gasosa. 40f. Santa Maria, RS. Dissertação (Mestrado em Medicina Veterinária) - Programa de Pós-graduação em Medicina Veterinária, Universidade Federal de Santa Maria.

16 Neglia G., Gasparrini B., Di Brienza V.C., Di Palo R., Campanile G., Presicce G.A. \& Zicarelli L. 2003. Bovine and buffalo in vitro embryo production using oocytes derived from abattoir ovaries or collected by transvaginal follicle aspiration. Theriogenology. 59:1123-1130. 
17 Olivier N.S., Palma G.A. \& Alberio R. 1998. In vitro production of bovine embryos in water bath. Theriogenology. 49: 211.

18 Oyamada T., Iwayama H. \& Fukui Y. 2003. Bovine blastocyst production by an individual oocyte culture during IVM/ IVF/IVC using a chemically defined medium. Theriogenology. 59: 348.

19 Palma G.A., Clement-Sengewald A., Berg U. \& Brem G. 1992. Role of the embryo number in the development of in vitro produced bovine embryos. Theriogenology. 37: 271.

20 Palma G.A., Olivier N., Alberio R.H. \& Brem G. 1998. In vitro development and viability of bovine embryos produced without gassed incubator. Theriogenology. 49: 213.

21 Parrish J.J., Susko-Parrish J.L., Leibfried-Rutledge M.L., Critser E.S., Eyestone W.H. \& First N.L. 1986. Bovine in vitro fertilization with frozen-thawed semen. Theriogenology. 25: 591-600.

22 Pinto M.G.L., Alves D.F., Rauber L.P., Sá Filho M.F., Mezzalira A., Bernardi M.L., Silva C.A.M. \& Rubin M.I.B. 2002. Holding bovine oocytes on equine follicular fluid for IVP. Theriogenology. 57: 736.

23 Rauber L.P. 2003. Líquido folicular bovino na produção in vitro de embriões bovinos. 46f. Santa Maria, RS. Dissertação (Mestrado em Medicina Veterinária) - Programa de Pós-graduação em Medicina Veterinária, Universidade Federal de Santa Maria.

24 SAS INSTITUTE (Cary NC) 1998. SAS user's guide: Statistical Analysis, Release 6.12. 2576p.

25 Schwartz J., Schneider M.R., Rodrigues J.L. \& Reichenbach H-D. 1998. Effect of short-term storage of bovine oocytes in different media and temperatures on the subsequent in vitro embryo development. Theriogenology. $49: 217$.

26 Shi D.S., Avery B. \& Greve T. 1998. Effects of temperature on in vitro maturation of bovine oocytes. Theriogenology. 50: 667-674.

27 Suzuki T., Sumantri C., Khan N.H.A., Murakami M. \& Saha S. 1997. Development of a simple, portable carbon dioxide incubator for production of bovine IFV embryos. Theriogenology. 43: 330.

28 Twagiramungu H., Morin N., Guilbault L.A., Sirard M.A. \& Bousquet D. 1998. Media and time of oocytes transport influence their developmental competence for in vitro production of bovine embryos. Theriogenology. 49: 299.

29 Ward F.A., Enright B.P. \& Boland M.P. 2000. Effect of group size and oocyte to medium volume post-fertilization on the development of bovine embryos in vitro. Theriogenology. 53: 306.

30 Wolf E., Boxhammer K., Brem G., Prelle K., Reichenbach H.D., Reischl J., Santl B., Schernthaner W., Stojkovic M., Wenigerkind H. \& Zakhartchenko V. 1998. Recent progress in the in vitro production and cloning of bovine embryos. Arquivos da Faculdade de Veterinária UFRGS. 26 (Supl): 160-177. 